\title{
MÚSICA DA TERRA DOS FARAÓS: APRENDIZAGENS DE ANTTONIETA DE SOUZA NUMA VIAGEM AO EGITO
}

\author{
Ednardo Monteiro Gonzaga do Monti ${ }^{1}$ \\ lattes.cnpq.br/1728209127429787
}

\begin{abstract}
Resumo: O presente estudo tem como horizonte as aprendizagens da professora Anttonieta de Souza na viagem que realizou ao Egito na década de 1950. Com base na série de artigos intitulada "Minhas impressões sobre o Egito", as perguntas que norteiam o texto são: quais tradições e culturas musicais egípcias a artista apresentou aos leitores da Revista do Conservatório Brasileiro de Música? O que aprendeu com os estudos arqueológicos e históricos sobre a música e os músicos da terra dos faraós? Os escritos da cantora dos palcos de concerto do Rio de Janeiro, publicados no periódico oficial da instituição de ensino superior de música que ela dirigia, permitem interpretar que as bases da tradição musical daquele povo eram os rituais religiosos, os mitos, as festas populares, as canções de trabalho, as fanfarras militares e as lendas. E que os estudos musicológicos sobre a antiguidade, com os quais Anttonieta teve contato na viagem, ressaltam que os instrumentos achados nos sítios arqueológicos possibilitaram repercutir timbres que há milhares de anos não soavam; e também conhecer as vestimentas e adornos feitos com flores de lótus que cantores e instrumentistas utilizavam; e ainda, adquirir informações sobre as grandes famílias de músicos que funcionavam como espécies de dinastias artísticas.
\end{abstract}

Palavras-chave: Viagem; Educação musical; Cultura egípcia.

\section{MUSIC FROM THE PHARAOH'S LAND: LEARNING OF ANTOINETTA DE SOUZA ON A TRIP TO EGYPT}

\begin{abstract}
This study focuses on the learnings of Professor Anttonieta de Souza during her trip to Egypt in the 1950s. Based on the series of articles entitled "Minhas impressões sobre o Egito" (My impressions about Egypt), the questions guiding the study are as follows: What Egyptian traditions and musical culture did the artist present to the readers of the Revista do Conservatório Brasileiro de Música (Brazilian Conservatory of Music's Magazine)? What did she learn from archaeological and historical studies about music and musicians of the Pharaohs's Land? The writings of the singer who graced the stages of Rio de Janeiro, published in the official journal of the Conservatório Brasileiro de Música that she directed herself, allow for the im-

${ }^{1}$ Doutor em Educação. Professor da Universidade Federal do Piauí (Brasil). Contato: ednardomonti@gmail.com.
\end{abstract}


pression that the nucleus of the Egyptian musical culture were the religious rituals, myths, the popular parties, Work songs, military fanfare and legends. What's more, her work that focuses on the antique music culture of Egypt emphasizes that instruments found on archaeological sites made the reverberation of timbres possible that for thousands of years did not sound; investigates the garments and accessories made from lotus flowers that singers and instrumentalists used; and considers the large families of musicians who functioned as if they were, to some extent, artistic dynasties.

Keywords: Travel; Music education; Egyptian culture.

\section{Introdução}

Iria percorrer os mesmos lugares visitados em 1876 pelo nosso magnânimo Imperador D. Pedro II, satisfazendo, dêste modo, a desejo que em mim se manifestara e permanecera, desde minha infância, quando vi, pela primeira vez, a sessão de egiptologia do nosso Museu Nacional, por êle trazida. (SOUZA, 1956, p. 15).

A epígrafe deste texto demonstra o encanto da professora de música Anttonieta de Souza (1893-1976) pela cultura egípcia; ao mesmo tempo, reflete sua fascinação pela história do Brasil, pela figura do Imperador D. Pedro II e pelo Museu Nacional. Esse conjunto de admirações demonstra que lugares impregnados de memórias podem proporcionar viagens no imaginário infantil e que incitam itinerários reais na vida adulta, como aconteceu com a cantora brasileira. Então, entendo que o desejo e o longo planejamento da artista para a viagem à terra dos faraós caracterizaram-se como uma busca repleta de expectativas para o que pode ser inesperado, para a aventura de trilhar um caminho percorrido por outros, para os novos saberes, vivências e experiências.

$\mathrm{O}$ "Dicionário bio-bibliográfico de mulheres ilustres, notáveis e intelectuais do Brasil" apresenta Anttonieta de Souza como natural do estado do Rio de Janeiro, nascida na cidade de Cantagalo, filha do casal Antonio Albuquerque Souza e Balbina Maria de Albuquerque Souza. A publicação menciona que o pai da cantora era marechal do Exército, com formação em Engenharia Militar, e que também fez o Bacharelado em 
Ciências Físicas e Naturais. Sobre a professora, o dicionário sinaliza que ela começou seus estudos musicais com aulas ministradas por Frederico Mallio; que suas formações pianística, teórica e de prática de solfejo foram direcionadas por Carlos Severiano Cavalier Darbilly, graduado em Paris, na escola pianística de Marmontel; que foi aluna de canto na classe da professora Stinco Pallermini. A publicação diz que a formatura em Canto de Anttonieta aconteceu em 1916, com distinção, e por concurso recebeu a medalha de ouro daquele ano, prêmio outorgado a cada 12 meses pelo Instituto Nacional de Música ao melhor formando (IGAYARASOUZA; PAZ, 2012).

Figura 1 - Fotografia de Anttonieta de Sousa. Fonte: Acervo Histórico da Biblioteca do Conservatório Brasileiro de Música.

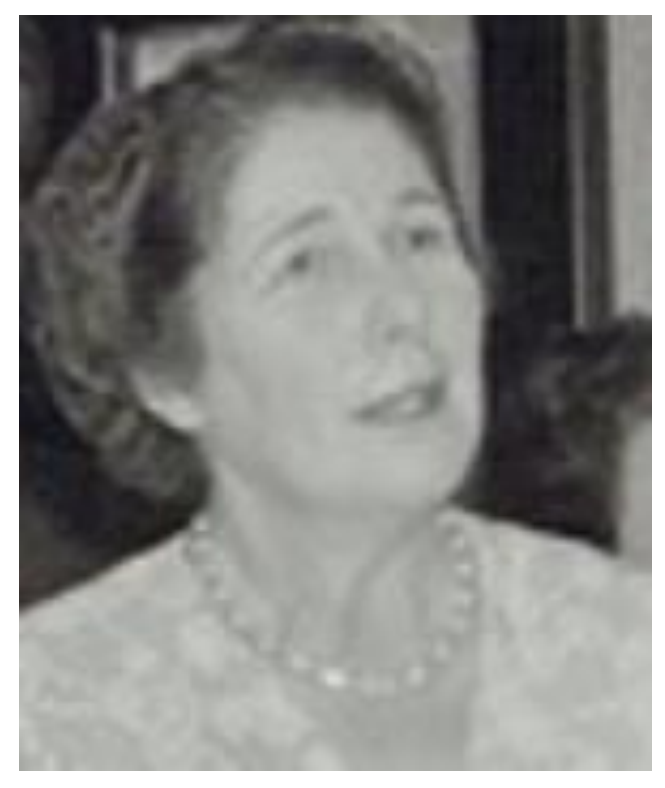

O percurso de Anttonieta de Souza e suas aprendizagens na terra dos faraós é a jornada proposta no presente estudo. O corpus documental mobilizado neste trabalho é formado por uma série de artigos, denominada pela artista brasileira como "Minhas impressões sobre o Egito". Os textos são relatórios prestados às comunidades de artistas e acadêmicos transeuntes na vida cultural do Rio de Janeiro emtão capital da República -, sobretudo aos discentes e docentes do Conservatório Brasileiro de Música (atual Conservatório Brasileiro de Música - Centro Universitário), Escola Nacional de Música (hoje, Escola de Música da Universidade Federal do Rio de Janeiro); e aos colegas de trabalho e frequentadores do Theatro Municipal do Rio de Janeiro.

Em outras palavras, por meio dos relatórios das viagens, publicados em forma de artigos, em sete números da Revista do CBM (Conservatório Brasileiro de Música), nos anos de 1956 e 1957, a professora de música, Anttonieta de Souza, apresentou aos seus pares, aos discentes e ao público - frequentadores das casas de concertos da então capital da 
República - os seus novos conhecimentos, as aprendizagens resultantes de suas viagens. Assim, conjuntamente, justificou suas ausências dos palcos e instituições de ensino de música do Distrito Federal.

A cantora foi uma mulher engajada na vida artística e política no Rio de Janeiro. Em um levantamento realizado no Jornal do Brasil, na década de 1930, seu nome é constante no que se refere ao movimento dos professores do Instituto Nacional de Música, no ano de 1932, por melhores condições de trabalho; e também entre os artistas do corpo de cantores do Theatro Municipal do Rio de Janeiro, em 1933, que reivindicavam maiores salários para os efetivos, além de cachês mais expressivos para os artistas convidados ou com contrato temporário. As marcas da professora e cantora nesse impresso também aparecem, por diferentes anos, nas notas dos críticos musicais que, na maior parte das vezes, ressaltavam a beleza de sua voz e o seu aprimoramento técnico. A imprensa ressalta ainda a frequência do presidente Getúlio Vargas nos recitais de Anttonieta nas instituições artísticas e de ensino de música.

Entre as instituições em que atuou no Rio de Janeiro, destaca-se sua atuação na criação do Conservatório Nacional de Música, em 1936, com um grupo de músicos nacionalistas - formado por Amália Fernandez Conde, Ayres de Andrade, Rossini da Costa Freitas e Roberta de Souza Brito, sob a liderança de Oscar Lorenzo Fernândez. Inspirado pelas novas metodologias do ensino da música, o grupo decidiu fundar essa escola de música para trabalhar com ideias musicalmente livres, onde todos os professores seriam sócios, com os mesmos direitos e deveres. Onde "não haveria salários, haveria produção" (CONSERVATÓRIO BRASILEIRO DE MÚSICA, 2011, p. 15). A proposta se configurava quase como uma cooperativa de professores que buscavam a qualidade do ensino e que, sobretudo, estavam abertos às inovadoras propostas metodológicas. Importante destacar que todos eram professores condecorados com a Medalha de Ouro do Instituto Nacional de Música, que discordavam das ideias conservadoras da instituição que tem origem, conforme Siqueira (1972), no Conservatório de Música instituído por D. Pedro II, em 1848. 
Após a morte de Oscar Lorenzo Fernândez, em 27 de agosto de 1948, Anttonieta é eleita diretora geral da Sociedade Civil Conservatório Brasileiro de Música, instituição mantenedora do Conservatório Brasileiro de Música. Uma das principais marcas deixadas pela nova diretora aconteceu logo no início de sua gestão, por ocasião da criação do primeiro curso de Especialização em Iniciação Musical do Brasil, elaborado para a formação de professores, sob a liderança de Liddy Chiaffarelli Mignone (CONSERVATÓRIO BRASILEIRO DE MÚSICA, 2014, p. 15). O curso foi tão bem aceito e bem-sucedido que, em dezembro de 1950, fundou-se o Centro de Estudo da Iniciação Musical da Criança do Conservatório Brasileiro de Música, cujas atividades iniciaram-se, efetivamente, em 1951, a partir da organização de uma biblioteca especializada. Nesse momento, destaca-se a oferta do curso de extensão universitária Psicologia Infantil e as Artes, ministrado pela psicóloga Noemy Silveira Rudolf.

Juntamente com Igayara-Souza (2011), no estudo sobre a produção de mulheres que dividiam suas vidas - "Entre os palcos e páginas: a produção escrita de mulheres sobre música na história da educação musical do Brasil" - é possível destacar que, a partir de 1929, Anttonieta de Sousa iniciou sua carreira também como autora. A cantora atuou como crítica musical no Diário da Noite, como articulista na Revista Illustração Musical e na Revista da Associação Brasileira de Música. Também foi idealizadora e redatora-chefe da Revista do CBM (Conservatório Brasileiro de Música), conferencista e autora de livros especializados em Canto. É de Igayara-Souza (2011, p. 254) a constatação e afirmação de que a artista foi, "sem dúvida, a cantora que mais uniu a prática artística à produção escrita" no Brasil.

Dentre as produções escritas pela cantora e educadora musical, estão suas experiências na viagem à terra dos faraós, publicadas na revista em que ela atuava como redatora-chefe. Um periódico oficial da instituição de ensino superior de música da qual participou da fundação e que, posteriormente, veio a dirigir por quase três décadas, na cidade do Rio de Janeiro. A imagem do pentagrama musical perpassando a sigla do Conservatório e as claves de Sol, Fá e Dó, na terceira linha, parecem indicar que as diferentes vozes eram consideradas na pauta da revista. 
Como consta na da capa do primeiro número, com tiragem de cinco mil exemplares, a Revista do CBM começou a circular em outubro de 1955. Entretanto, foi no segundo número desse impresso - também com cinco mil cópias, no primeiro trimestre de 1956 - que a artista publicou o primeiro artigo da série "Minhas impressões sobre o Egito". Com o pensamento de Viñao Frago (2007), compreendo que a elaboração de informes, livros ou diários resultados de viagens, quando compartilhados, podem educar, uma vez que possibilitam a circularidade de saberes e modelos de uma realidade distinta. É nesta circunstância que penso serem relevantes análises e interpretações dos textos de Anttonieta de Sousa.
Figura 2 - Capa da Revista do CBM, Anno I, n. 1, 1955. Fonte:

Acervo Histórico da Biblioteca do

Conservatório Brasileiro de Música.

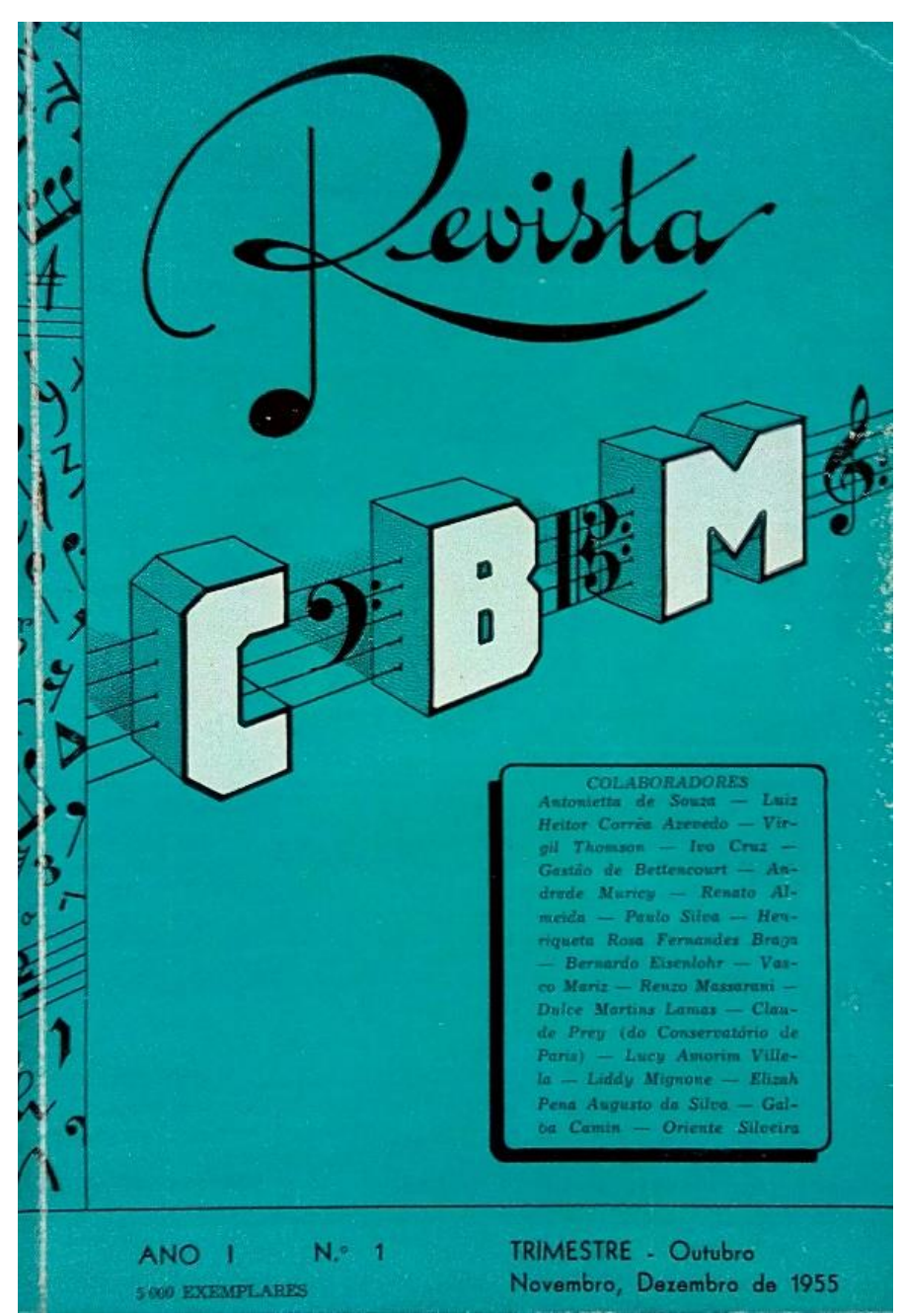

Considerando a viagem da educadora musical ao Egito, pelos números da Revista do CBM - publicados entre 1956 e 1957 -, como principal fonte documental do presente trabalho, as perguntas que norteiam este texto são: quais tradições e culturas musicais egípcias a artista apresentou aos seus leitores? O que aprendeu com os estudos arqueológicos e históricos sobre a música e os músicos da terra dos faraós?

Para delinear os contornos deste artigo, organizei o texto em duas seções. A primeira parte é dedicada às questões culturais da música egípcia, aprendidas in loco e descritas pela viajante em seus artigos. Sigo, no 
segundo tópico, com os aspectos da música e dos músicos do Egito na antiguidade, abordados por Anttonieta de Sousa nas páginas da Revista do Conservatório Brasileiro de Música.

\title{
Tradição como base da cultura musical
}

\begin{abstract}
Quem ouviu essa música nas suas fontes de origem, pura na sua forma e singelamente interpretada, (como aliás, eu tive oportunidade de ouvir, quando percorri o Egito, desde Alexandria até Assuam, parando ora aqui ora ali, em grandes cidades e pequenas vilas), jamais se olvidará da beleza da sua sonoridade e de seu ritmo de encantador sortilégio. (SOUZA, 1957b, p. 12).
\end{abstract}

Uma constatação central de Anttonieta de Souza (1957a, p. 16) em sua viagem à terra dos faraós é a conjuntura das melodias folclóricas e dos cantos litúrgicos das Igrejas Coptas que "fizeram sobreviver sob as inclemências dos séculos, conservando-as" até o início da segunda metade do século XX - quando esteve naquele país - e que chega aos nossos dias. Isso significa que Anttonieta, em seu itinerário, teve contato com possíveis fragmentos, frases ou alguns outros vestígios de linhas musicais básicas.

Segundo seu relato de viagem na Revista do $C B M$, esta transmissão ocorreu pelo movimento dos primeiros "cristãos do Egito a permanecerem na Igreja Copta, [assim como] a tradição musical dos templos da época do paganismo" (SOUZA, 1957a, p. 16). Com outras palavras, os religiosos alteraram as letras das músicas já existentes, transmitidas oralmente na cultura egípcia. Os convertidos ao cristianismo introduziram a teologia monoteísta, uma nova doutrina que abarcou uma parte daquele povo, os antigos cânticos, "acompanhando a nova liturgia [...] as melopeias executadas durante os antigos ritos" (SOUZA, 1957a, p. 16).

Considerando os estudos arqueológicos, a viajante ressalta que as descobertas sobre as comemorações que aconteciam no Egito corroboram o elevado grau de cultura musical do país no decorrer da Antiguidade Oriental. Nesta perspectiva das festas, Anttonieta comenta a descrição do "geógrafo" e "historiador" grego Hérodote (485 a.C.-420 a.C.) sobre as 


\section{Revista de História e \\ Historiografía da Educação}

briosas festas dedicadas à Bubastis - Diana Egípcia -, por sua extraordinária grandiosidade que envolveu milhares pessoas que desciam o Rio Nilo em embarcações profusamente decoradas, "fazendo sentir o ruído das Castanholas, ao som das flautas simples e duplas, acompanhadas pela multidão batendo as mãos cadenciadamente, que tomavam parte da festa em honra aquela Deusa" (SOUZA, 1957a, p. 17).

Simultaneamente, a cantora

Figura 3 - Egípcios com cítaras e flauta dupla. Fonte: Revista do $C B M$, ano II, n. 6, 1957. Fonte: Acervo Histórico da Biblioteca do Conservatório Brasileiro de Música.

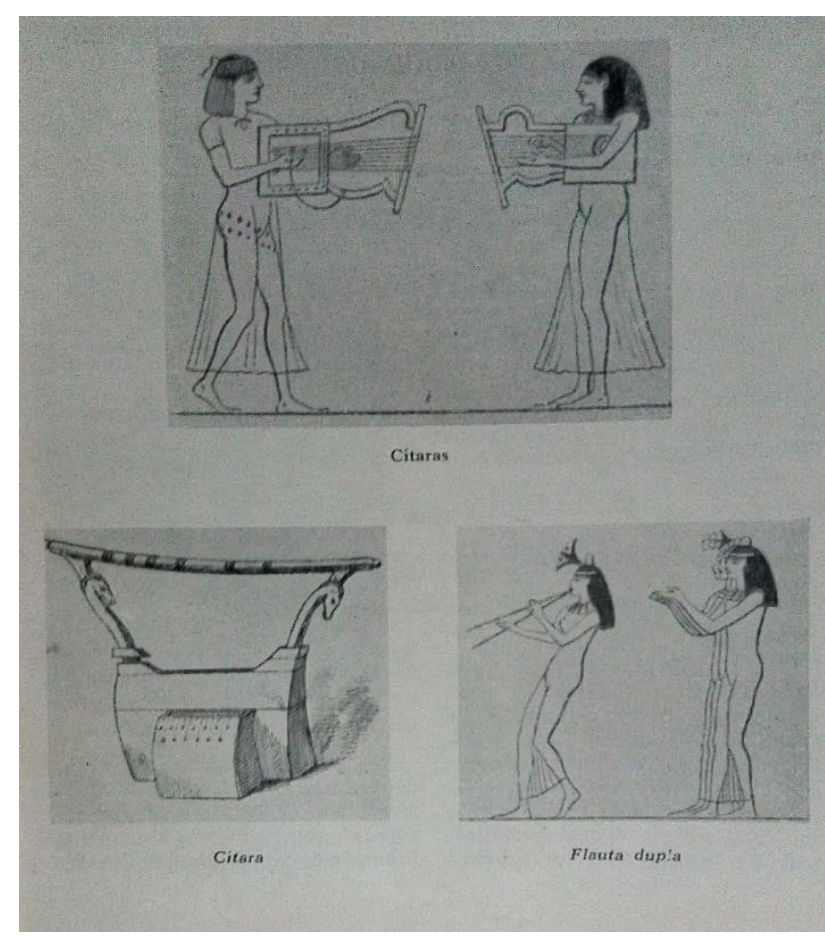

celebração mencionada.

A professora de música, além de apresentar aos leitores suas impressões sobre a viagem, coloca na série de artigos imagens dos instrumentos pelo qual a música daquele tempo era executada e, consequentemente, transmitida pela tradição. Também mostrou aos seus leitores grande parte com formação em música, portanto, capaz de ler e analisar partituras - a grafia da versão de uma peça musical (Canção dos Barqueiros do Nilo), que teve acesso naquela jornada às margens e águas do viajante traz em seus artigos sobre a viagem ao Egito a festa de proporções gigantescas planejada e realizada por Ptolomeu Soter II (faraó da Dinastia Ptolemaica do Egito - 143 a.C.-81 a.C.), para a qual foi preparada uma apresentação de canto coletivo, constituído por um grupo de 1.200 integrantes, cuja vozes foram acompanhadas por centenas de instrumentistas que executaram 300 cítaras e um grande quantitativo de flautas. Para ilustrar e fomentar o imaginário do seu leitor, Anttonieta de Souza utilizou a imagem ao lado (figura 3), na qual aparecem egípcios executando os instrumentos utilizados na 
Rio Nilo, paisagem onde a referida celebração aconteceu. A presença destas músicas no texto expressa que a viajante escreveu os artigos sobre sua viagem para um público específico, músicos profissionais, em formação ou amadores.

Figura 4 - Partitura da Canção dos barqueiros do Rio.

Fonte: Revista do CBM, ano II, n. 6, 1957. Fonte: Acervo

Histórico da Biblioteca do Conservatório Brasileiro de Música.

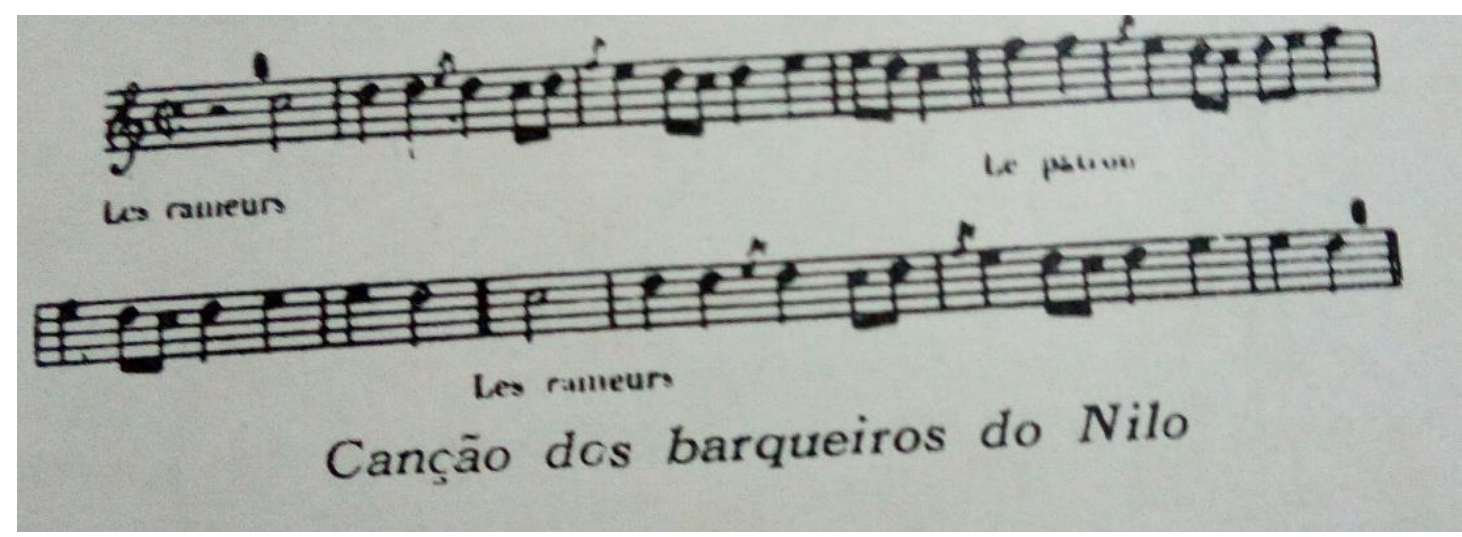

Anttonieta de Sousa (1957a, p. 18), após apresentar imagens dos instrumentos e uma versão da representação gráfica da música que soava na festa do Rio Nilo, adentra nos aspectos musicais da mitologia egípcia. A cantora explica "que a flauta é atribuída à concepção do Deus Osiris, que a fez do lótus, inspirado no esguio pedúnculo que sustenta a flor dessa planta aquática, que aparece inúmeras vezes exercendo influência preponderante, quer na vida privada, quer na religiosa da época faraônica" pelo fato de ter surgido, "por ter nascido e viver dentro d'água, que era considerada pelos povos da Antiguidade como sendo um dos elementos sagrados da natureza”.

Por um lado, a brasileira em viagem ao Egito surpreende-se com a relação entre a música e a mitologia, articulação que fazia o povo acreditar, na Antiguidade, que a mobilização artística dos sons intervia sobrenaturalmente, como uma atuação dos deuses, uma intervenção divina no mundo. Por outro lado, na esfera humana, Anttonieta de Sousa lamenta que o povo egípcio poderia não ter consciência de "que a música incitava os indivíduos às paixões vis e aos brutais instintos” (SOUZA, 1957a, p. 19) 
e que, por isso, acabava transferindo para as divindades mitológicas como gênios do mal - as responsabilidades as cruéis ações realizadas de maneira impensadas pelos membros daquela comunidade.

Outra questão desfavorável sobre a música, que Anttonieta de Sousa (1957a, p. 20) lamentou em suas memórias da viagem ao Egito, foram as narrativas do grego Diodore de Sicile. (90 a.C.-30 a.C.). Esse "historiador" acreditava que os egípcios criam que a dedicação ao estudo da arte musical era uma ação sem utilidade, negativa e contraproducente às pessoas, porque "inervava a alma e tornava os homens afeminados". Diodore de Sicile constatou ainda que esta opinião circulava entre alguns, sendo "flagrante na minoria do povo com espírito contristado, [afirmando] que maiores riquezas ostentaram na Antiguidade Oriental" (SOUZA, 1957a, p. 20). Para mudar o rumo desta passagem, que Anttonieta de Sousa apresentou como "desconfortável", a viajante termina o resumo desse contexto adverso valorizando o fazer musical da cultura egípcia, com as seguintes palavras: "E, naqueles pregressos dias, a música continuou a ser ouvida em todos os lugares, ligada sempre à vida dos egípcios de todas as classes sociais" (SOUZA, 1957a, p. 20).

Outra questão negativa que, segundo Anttonieta de Sousa, sobressaía na cultura musical do Egito faraônico era em relação aos direitos das mulheres. A cantora destaca que a música religiosa, "executada pelos sacerdotes cantores no recinto dos templos, só era ouvida por homens" (SOUZA, 1956, p.21), pois somente eles "gozavam do privilégio de serem iniciados, e por isso podiam assistir ao ritual e participar do 'divino cerimonial' da adoração de um deus".

Percebe-se, então, que a professora brasileira, que dirigia uma prestigiada instituição de ensino superior de música, analisava a salvaguarda dos homens em contraposição ao cerceamento das mulheres. Anttonieta de Sousa relata ainda ter aprendido que somente no culto a uma deusa - a celebração religiosa dedicada à Osires, em Abydos - era onde acontecia a exceção, um evento diferenciado, que fugia à regra sobre a música nos templos. Uma vez que no templo de Osires, uma deusa, não havia cânticos ou se quer um instrumento poderia ser tocado. 
Dentre as diferentes maneiras, em que a tradição era a base da cultura musical na sociedade egípcia faraônica, a viajante destacou para os leitores da Revista do $C B M$ as fanfarras militares, entretanto, como rústicas e elementares. É importante pensar que a concepção musical da professora e cantora era bastante apurada, pois décadas antes de ir ao Egito, Anttonieta de Souza conheceu orquestras de vários países, ganhando, em 1923, o Prêmio Viagem, do Instituto Nacional de Música, no Rio de Janeiro. O concurso visava o aperfeiçoamento dos melhores discentes da instituição na Europa. Sendo assim:

Entre 1924 e 1928, [Anttonieta de] Sousa cantou em companhias líricas e em concertos na França, Itália, Bélgica, Espanha, Inglaterra, Portugal. Em estágio em Paris (1925, 1926 e 1927), estudou Declamação Lírica com Albert Carré no Conservatório Nacional de Música e Declamação. Foi primeira mezzo-soprana do Teatro Real de Madrid (1926 e 1927), estreando com Sansão e Dalila de Saint-Saëns. Atuou também nos teatros Fenice de Veneza, Verdi de Pádua, Principal de Valença. (IGAYARASOUZA; PAZ, 2012, p. 13).

Figura 5 - Conjunto de músicos militares.

Fonte: Revista do CBM, ano II, n. 6, 1957.

Fonte: Acervo Histórico da Biblioteca

do Conservatório Brasileiro de Música.

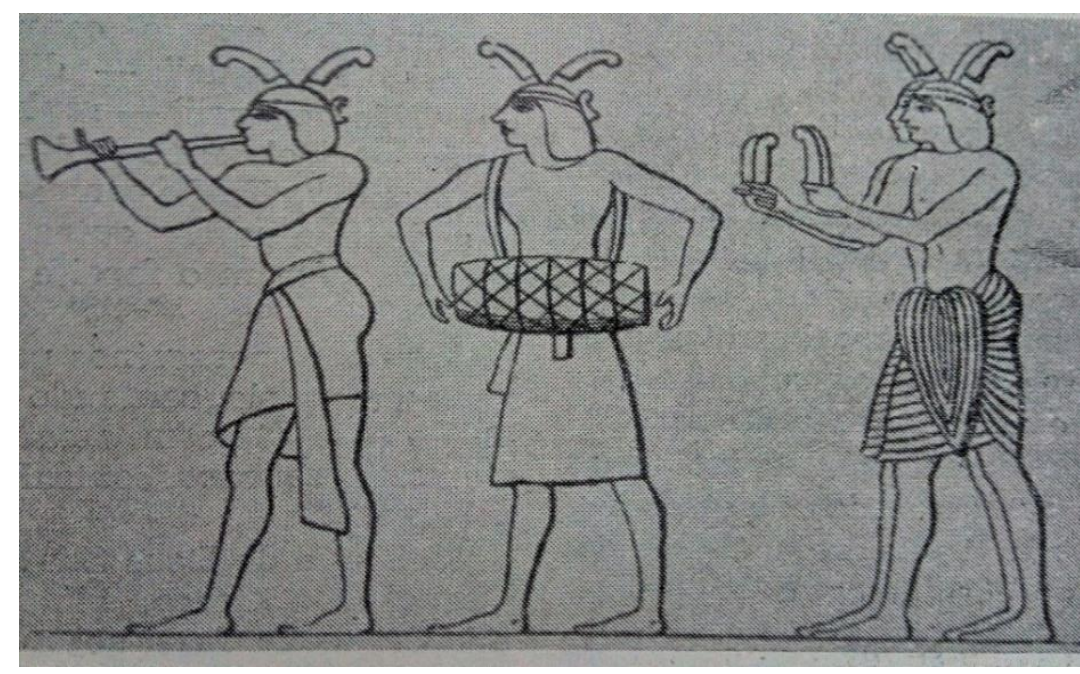

Sobre este tipo de grupo de formação musical (as fanfarras militares), que considerou menos sofisticada, Anttonieta de Souza disponibilizou, na série de artigos "Minhas impressões sobre o Egito", a imagem de uma expressão artística que, também, era base da transmissão da música nos tempos dos fa- 
raós. Conforme a imagem que segue, constatam-se apenas três tipos de instrumentos: trombeta, tambor e tige duplo, na ordem da esquerda para a direita.

A então diretora geral do Conservatório Brasileiro de Música trouxe da viagem uma coleção de lendas dos antigos egípcios - com enredos ligados à música -, mais uma tradição pela qual a canção perpassava a cultura daquele país. Essas histórias eram transmitidas pela comunicação oral como fábulas, intituladas, por exemplo: "O Leão dança com a Gazela; O Crocodilo canta acompanhando-se ao Alaúde; O Burro tocador de harpa; e Senhora Rata dão ordens ao Gato" (SOUZA, 1957b, p. 13).

Por perceber a fragilidade da música militar no Egito, a professora de canto viajante destaca que o patrimônio da música antiga daquele país é formado pelas melodias das canções de dança que, principalmente, nas festas populares, operam como atrativos encantadores. As suaves e cativantes canções de ninar, os cantos religiosos, "as tristes e alegres canções de trabalho, as dolentes canções de amor as quais, talvez, constituam o maior acervo artístico [da] música folclórica egípcia do Vale do Rio Nilo, em igualdade, em número e valor, com a dos outros países" (SOUZA, 1956a, p. 11).

Por tudo isso, percebe-se, então, que a viagem da cantora brasileira à terra dos faraós foi um encontro de profunda troca, de articulação entre duas culturas distintas. Nas palavras da educadora musical:

As cenas por mim representadas nos palcos dos teatros onde, encarnando o papel de Ammeris, da ópera Aida, fui a arrogante princesa faraônica, todo esse passado, ora real, ora fictício, povoava-me desordenadamente o cérebro naquele instante. (SOUZA, 1956a, p. 20).

Anttonieta de Sousa, em sua viagem ao Egito, fez uma articulação das suas experiências dos palcos do Rio de Janeiro e do mundo com a cultura oriental, ampliado o que Bourdieu (1982) chama de "capital cultural no estado incorporado". Como explica Silva (2013, p. 110), "o deslocamento no tempo e no espaço proporcionado pelas viagens pode levar a uma releitura da própria cultura, como também à ampliação dos horizontes em relação à compreensão do outro, o diferente”. A terra dos faraós se 
misturava na mente da cantora com cenários das óperas em que atuou, expandindo sua concepção sobre a música e os músicos egípcios.

\title{
Estudos e investigações sobre a música e os músicos do Egito
}

\begin{abstract}
Os arqueólogos e Egiptólogos que continuam revolvendo e pesquisando o solo do Vale do Nilo realizaram, recentemente, surpreendentes e maravilhosas descobertas no patrimônio arqueológico da era faraônica, que se encontrava soterrada naquela região. Instrumentos de música em perfeito estado de conservação, pinturas e esculturas, murais de templos e de tumbas, foram encontrados nas profundezas daquela terra, possibilitando, destarte, serem determinadas com mais precisão as diferentes épocas por que passaram a arte musical da milenária civilização egípcia. (SOUZA, 1956, p. 33).
\end{abstract}

Ao tratar das músicas e dos músicos do Egito, a professora de canto apresentou aos leitores da Revista do CBM, conforme o texto supracitado, que em sua viagem buscou informações científicas para fundamentar os relatos compartilhados com seu público, aquelas pessoas que consumia a cultura musical difundida pelo periódico. O calibre, a relevância e a utilidade daqueles dados eram bastante significativos; e por meio dessas informações a viajante, possivelmente, despertou o interesse de muitos pelos seus artigos. Porque, como mencionou, doravante ao contato com esses cientistas, foi viável divulgar a experiência de escutar os timbres e as "sonoridades autênticas de instrumentos usados em períodos de eras pregressas da cultura musical egípcia, os quais, até então, se encontravam ocultos no próprio solo sobre o qual luziram com inigualável esplendor, as cortes faraônicas" (SOUZA, 1956, p. 33).

Percebe-se, então, que a professora de canto seguiu uma prática que ganhou mais forma no século IX, e que ao longo do século XX se consolidou: a realização de viagens, "tendo por objetivo o conhecimento de instituições consideradas, de alguma maneira, exemplares e localizadas em países que passavam por algum processo [de] desenvolvimento" (PINTASSILGO, 2010, p. 67). E, também, de maneira semelhante, se ins- 
taurou a prática de escrever e difundir "relatórios na sequência das viagens, documentos que nos permitem hoje aceder às imagens e representações que foram construídas a partir desse olhar sobre o estrangeiro, e que vão do encantamento a certo distanciamento crítico" (PINTASSILGO, 2010, p. 67).

Nessa perspectiva, de circulação e difusão do saber, no Brasil, sabese, com base nos estudos musicológicos realizados no Egito, que na primeira década da segunda metade do século XX, era exequível a análise dos timbres de diferentes instrumentos, da "extensão das suas escalas musicais e da possível polifonia primitiva, como também, elaborar a restauração de antiquíssimos instrumentos" (PINTASSILGO, 2010, p. 67). Outrora, antes dessas descobertas, que a musicista brasileira teve a oportunidade de testemunhar na viagem, os estudos históricos sobre a música no Egito eram realizados através de outras fontes, tais como: os baixosrelevos e as pinturas dos santuários de tempos remotos. Este avanço, proporcionado pela Arqueologia, foi uma das aprendizagens que mais impressionou a musicista, porque, como registou no seu artigo-relatório, estes procedimentos investigativos tornaram os pesquisadores:

[...] aptos a traçarem no panorama da História da Música a linha evolutiva da arte dos sons de um dos mais antigos povos da humanidade, desde o seu aparecimento nos primórdios da mais remota civilização, até os dias que estamos vivendo presentemente [1955], os quais se caracterizam pelos veementes anseios do homem contemporâneo em descobrir para dominar, todos os segredos e forças da natureza. (SOUZA, 1956, p. 32).

Pelo tom empolgante dessa parte do relatório-artigo da viagem, percebe-se que a cantora ficou bastante embevecida com as descobertas dos arqueólogos e com os estudos musicológicos do Egito. Porém, faz-se necessário pensar que estas importantes descobertas não eram e, como até a atualidade, não são, suficientes para suprir as demandas de fontes necessárias para abarcar a História da Música, desde os mais antigos povos civilizados até o início da segunda metade do século XX. Contudo, é bem verdade que algumas inferências e interpretações, a partir dos instrumentos encontrados, são bastante significativas, porquanto que por 


\section{Revista de História e}

Historiografia da Educação

meio desses objetos chegou-se, por "exemplo, à conclusão de que as harpas existentes no período dos reinados dos Faraós tinham de 4 a 22 ou 23 cordas, e eram horizontais ou verticais" (SOUZA, 1956, p. 32), conforme a imagem que Anttonieta compartilhou na revista da instituição de ensino de música que dirigia.

Figura 6 - Dr. Hans Hickman e sua esposa tocando instrumentos antigos.

Fonte: Revista do CBM, ano I, n. 5, 1956. Fonte: Acervo Histórico da Biblioteca do Conservatório Brasileiro de Música.

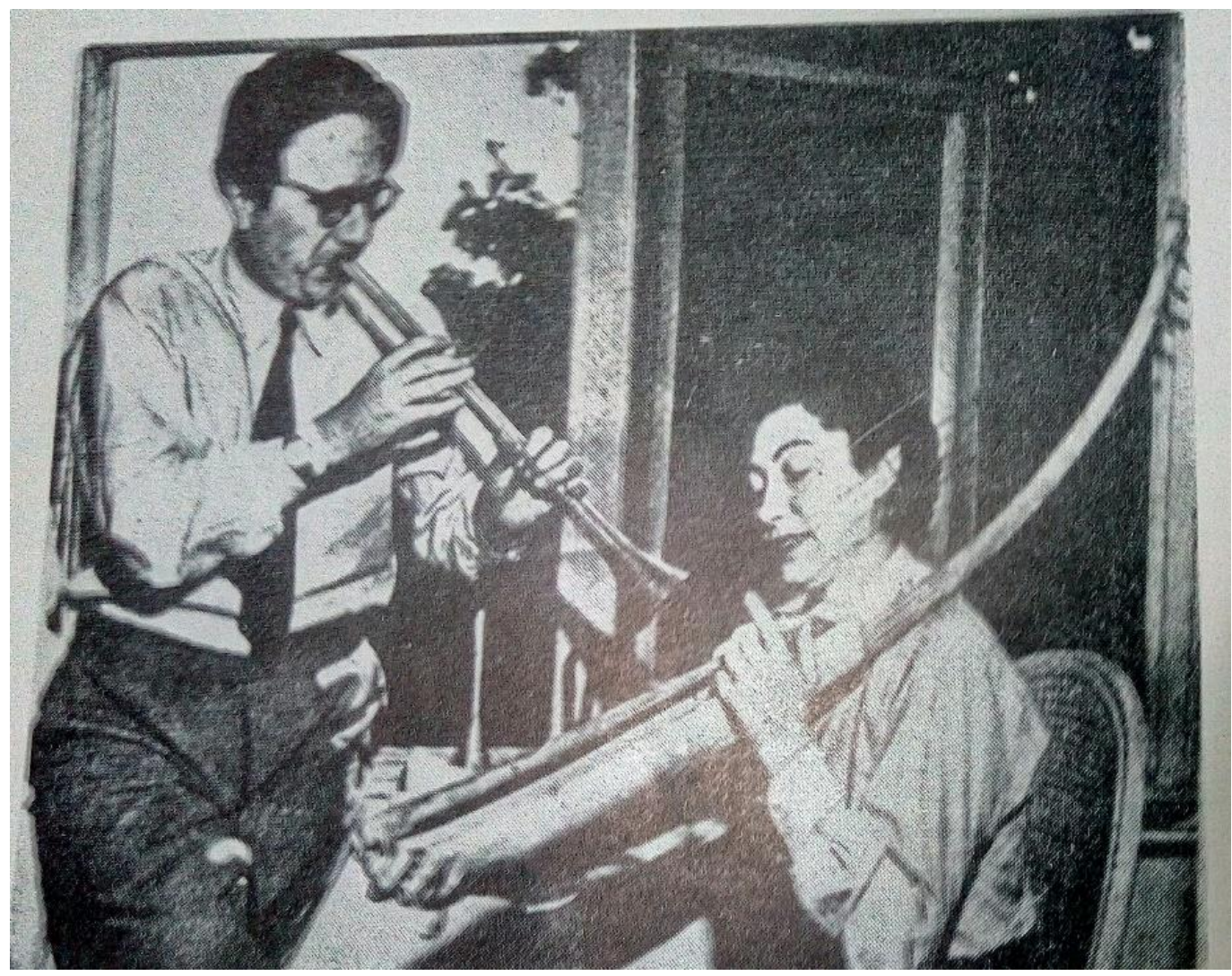

A redatora-chefe da Revista do CBM revela para seus leitores outros contatos com os achados arqueológicos de estudos históricos sobre os instrumentos musicais do Egito da Antiguidade, peças anteriores à época dos Faraós Cheops, Kephren e Mycerinus, que mandaram construir as pirâmides, pois, durante o reinado dos Faraós da IV dinastia (2723 a.C.-2563 a.C.), segundo históricos [...] restituídos à luz Horus, já existiam com suas formas definitivas, como a trombeta de Tout-Ankh-Amon" (SOUZA, 1956, p. 32), cujo registro consta na fotografia (figura 6). 
Além dos estudos sobre os instrumentos da Antiguidade, a cantora teve contato com pesquisas a respeito de vestimentas e adornos dos músicos do mundo egípcio. Estas pesquisas por ela mencionadas apontam que não eram exclusivamente as figuras divinas - os deuses, os faraós e as rainhas - que se enfeitavam com ornamentos feitos de flores. Como ratifica uma pintura vista em Thebas, na qual uma jovem instrumentista tocadora de tanbourah - tipo de guitarra que na atualidade ainda é utilizada pelos Árabes - tinha sobre a cabeça um enfeite composto de pétalas de flores de lótus.

Anttonieta de Sousa também ficou conhecendo que no Egito faraônico havia ainda numerosas dinastias de artistas dedicados à música. Como exemplo, a brasileira, em viagem ao oriente, ressalta a família Snofrou-Nofer, dentre os quais muitos membros foram músicos classificados como "Maitres des plaisirs du Pharaon" [Mestres dos prazeres do Faraó] (SOUZA, 1956, p. 37).

Sobre os estudos históricos e arqueológicos, Anttonieta de Souza ressalta que a música egípcia floresceu no decorrer dos reinados faraônicos, entre 2778 a.C.-2423 a.C. Depois, passou por muitas transformações, consequência de diferentes contatos e jornadas da arte musical estrangeira, atingindo o seu apogeu pelo intercâmbio, entre os anos de 1580 a.C. e 1090 a.C.

\section{Considerações finais}

As memórias da professora de canto Anttonieta de Souza, publicadas nas páginas da Revista do CBM, entre 1956 e 1957, permitem interpretar como foi realizar o sonho de conhecer a música dos faraós e refazer o inspirador trajeto do Imperador do Brasil D. Pedro II, rota que muito fomentou o imaginário da cantora na infância, quando ela visitou o Museu Nacional. Ler suas escritas de viagem é também, de alguma maneira, viajar ao Egito com Anttonieta de Souza, que deixou por um tempo os palcos e as salas de aula da cidade Rio de Janeiro, então Distrito Fede- 
ral, para conhecer as margens do Rio Nilo e adentrar nos sítios arqueológicos daquele país do Oriente.

Dentre outras aprendizagens, sua série de artigos denominado "Minhas impressões sobre o Egito" viabiliza perceber que a base da cultura musical daquele povo da Antiguidade oriental eram as canções populares. Verdadeiras "trilhas sonoras" das grandes festas que chegaram a contar com coros de 1.300 vozes, acompanhados por 300 instrumentistas. Como também o repertório cantado pelos trabalhadores na labuta do seu dia-a-dia, os cantos religiosos que soavam nos templos, os sons oriundos das fanfaras militares, os contos, os mitos e as fábulas com estórias referentes aos temas musicais.

Nas páginas da Revista do CBM, a educadora deixou registrados os estudos musicológicos embasados na Arqueologia com que teve contato através dos cientistas e que revelaram instrumentos de um passado distante e seus respectivos timbres; as vestimentas e os adornos feitos de flores de lótus que cantores e instrumentistas utilizavam, além das grandes famílias de músicos que funcionavam como espécies de dinastias.

\section{Referências}

BITTENCOURT, A. Dicionário bio-bibliográfico de mulheres ilustres, notáveis e intelectuais do Brasil. Rio de Janeiro: Pongetti, 1970.

BOURDIEU, P. A economia das trocas simbólicas. 5a edição. São Paulo: Perspectiva, 1982.

CONSERVATÓRIO BRASILEIRO DE MÚSICA. Plano de Desenvolvimento Institucional - PDI (2014-2019). Rio de Janeiro, 2014.

COSTA, C. M.; CARDEMAN, C. Musicoterapia no Rio de Janeiro: 19552005. Rio de Janeiro: Biblioteca de Musicoterapia, 2006.

IGAYARA-SOUZA, S.; PAZ, A. L. F. Trajetórias femininas memoráveis do século XX: uma perspectiva comparada do ensino especializado de música Portugal-Brasil. In: MOGARRO, M. J.; CUNHA, M. T. S. (org.). Atas do IX Congresso Luso Brasileiro de História da Educação - Rituais, espaços \& patrimónios escolares. Lisboa: Instituto de Educação da Universidade de Lisboa, 2012. 
IGAYARA-SOUZA, S. C. A. Entre palcos e páginas: a produção escrita por mulheres sobre música na história da educação musical do Brasil (1907-1958., São Paulo, FEUSP, 2011.

PINTASSILGO, J. Exemplaridade institucional e renovação pedagógica: reflexões a partir das viagens de professores do Instituto de Odivelas. $R e$ vista Brasileira de História da Educação, n. 22, p. 65-86, 2010.

SILVA, A. L. Ideias em movimento: viagens como horizonte na historiografia da educação. Roteiro, v. 1, p. 109-126, 2013.

SIQUEIRA, B. Do conservatório à escola de música: ensaio histórico. Rio de Janeiro, UFRJ, 1972.

SOUSA, A. Minhas impressões sobre o Egito. Revista do CBM, v. I, ano I, n. 3, p. 16-21, 1956.

. Minhas impressões sobre o Egito (continuação). Revista do $C B M$, v. I, ano II, n. 6, p. 16-21, 1957 a.

. Minhas impressões sobre o Egito (continuação). Revista do $C B M$, v. I, ano II, n. 7, p. 11-15, $1957 \mathrm{~b}$.

VIÑAO FRAGO, A. Viajes que educam. In: MIGNOT, A. C. V.; GONDRA, J. G. (org.). Viagens pedagógicas. São Paulo: Cortez, 2007.

Recebido em 12 de março de 2017. Aprovado em 03 de abril de 2017. 